Journal of Modern Mathematics and Statistics 4 (4): 137-142, 2010

ISSN: 1994-5388

(C) Medwell Journals, 2010

\title{
Analysis of Circular Consecutive-k-out-of-n:G Systems
}

\author{
M.A. El-Damcese \\ Department of Mathematics, Faculty of Science, Tanta University, Egypt
}

\begin{abstract}
The problem addressed is how applying a continuous-time homogeneous Markov process to evaluate availability, reliability and MTTF for circular consecutive-k-out-of-n: G system with repairman. In this study, assumed that the working time and the repair time of each component are arbitrarily distributed and every component after repair is as good as new. Each component is classified as either a key component or an ordinary one according to its priority role to the system repair. When the system displays a gradual degradation of its performance, its availability and reliability are then analyzed in terms of fuzzy success states. Key components have priority in repair when failed. By using a continuous-time homogeneous Markov process and the definition of the generalized transition probability, the state transition probabilities of the system are derived. Circular consecutive-7-out-of-10: $\mathrm{G}$ system with $\mathrm{r}$ repairman for an example is given to show the performance of the model.
\end{abstract}

Key words: Generalized transition probability, circular consecutive-k-out-of-n:G system, r repairman, availability, reliability, MTTF

\section{INTRODUCTION}

Redundancy is used in design to improve system reliability. A consecutive-k-out-of-n: $\mathrm{G}$ system is one kind of systems with redundancy. Suppose that $\mathrm{n}$ components are linearly (circularly) connected in such a way that the system works if and only if at least $\mathrm{k}$ consecutive components researches. This type of structure is called the linear (circular) consecutive-k-out-of-n:G system, denoted by linear (circular) $\mathrm{C}(\mathrm{k}, \mathrm{n}: \mathrm{G})$ in short. The consecutive-k-out-of-n: G system (both linear and circular) include the series and the parallel systems as special cases. For example, when $\mathrm{k}=\mathrm{n}$, the linear and circular consecutive-k-out-of-n:G system becomes the series system and when $\mathrm{k}=1$, the linear and circular consecutive-k-out-of-n: $G$ system becomes the parallel system. The problem of evaluating the subject of the reliability of the $C(k, n: G)$ system has been many studies (Kuo et al., 1990; Gera, 2000; Hwang et al., 2000; Chang et al., 2000; Rade, 1994). Through various studies of the $\mathrm{C}(\mathrm{k}, \mathrm{n}: \mathrm{G}$ or $\mathrm{F})$ system structure have been reported in the literature, little attention has been paid to such systems that are repairable (Zhang and Lam, 1998; Cheng and Zhang, 2001; Zhang et al., 2000; Zhang and Lin, 2000; Yam et al., 2003; Kuo and Zuo, 2003). In this study, we will analyze repairable circular $C(k, n: G)$ system with $\mathrm{r}$ repairman and provide a general formula to calculate $\mathrm{M}_{\mathrm{i}}$, the number of different case when the system is in state $-\mathrm{i}$. The state $-\mathrm{i}$ indicates that the system is working with $\mathrm{i}$ failed components in total. As an illustration, availability, reliability and MTTF of circular C $(7,10: \mathrm{G})$ system by using Laplace transform technique.
Assumptions: The system model to be studies is described as follows:

- The system is a circular $C(k, n: G)$ system with identical components. Each component may be in one of two possible states working or failed. The system works if and only if at least $\mathrm{k}$ consecutive components are working

- Let $\mathrm{X}_{\mathrm{i}}$ working time and the $\mathrm{Y}_{\mathrm{i}}$ repair time of any component $\mathrm{i}(\mathrm{i}=1,2, \ldots, \mathrm{n})$. All this random variables $X_{i}$ and $Y_{i}$ are mutually s-independent and identically exponentially or Weibull distributed with the parameters $\lambda>0$ and $\mu>0$, respectively

- All components are working at time $t=0$

- There are $r$ repairman in the system. Each component after being repaired is as good as new. If the system is in working state, the failed components are repaired according to the rule of the first-in first-out. If the system has failed. A key component will have a higher priority of repair than an ordinary component has. This means if $r$ repairman are simultaneously busy, all of them must switch over to repair key components from repairing ordinary components. If there are $>\mathrm{r}$ key components, the key components are repaired also based on the discipline of first-in first-out. If the number of key components is $<\mathrm{r}$, let each repairman repair one failed component. The remaining repairman are assigned to the key components according to the discipline of random selection

- While the system is in failed state, the components that have not failed will not fail 
- The probability for 2 or $>2$ components to fail in a very small time intervals negligible

Based on the model assumptions, the state of the system at time $t$, denoted by $N(t)$, may take the following possible values:

$N(t)=\left\{\begin{array}{l}0, \text { if at time } t, \text { all components work } \\ \text { and the system works }-1, \text { if at time } t, \\ \text { one component fails and the system works } \\ M \\ -(n-k), \text { if at time } t(n-k) \text { components fail } \\ \text { and the system works } 2, \text { if at time } t \\ 1 \text { components fail and the system fails } \\ M \\ (n-k), \text { if at time } t(n-k) \text { components fail } \\ \text { and the system fails (n-k+1), if at time } t \\ (n-k+1) \text { components fail and the system fails }\end{array}\right.$

According to the model assumptions when the working time and the repair time of every component in the system are assumed to be arbitrary distributed, then $\{\mathrm{N}(\mathrm{t}), \mathrm{t} \geq 0\}$ must form a continuous-time homogeneous Markov process with state space $\Omega=\{0,-1,-2, \ldots,-(\mathrm{n}-\mathrm{k})$, $2,3, \ldots,(\mathrm{n}-\mathrm{k}+1)\}$, the set of working states is: $\mathrm{W}=\{0,-1$, $-2, \ldots,(n-k)\}$ and the set of failed states is: $F=\{2,3, \ldots,(n-$ $\mathrm{k}+1)\}$.

Notation: $N(i, k, n)$ number of ways to place $i$ identical balls in $\mathrm{k}$ different urns such that each urn contains at most $n$ balls:

$N(t)$ : State of system at time $t$

$\mathrm{P}_{\mathrm{im}(\mathrm{i})}(\mathrm{t})=\operatorname{Pr}\{\mathrm{N}(\mathrm{t})=$ the $\mathrm{m}$ th case of state $\mathrm{i} \mid \mathrm{N}(\mathrm{t})=\mathrm{i}\}, \mathrm{i} \in \Omega$

$\operatorname{Pm}_{(i) j}(\Delta t)=\operatorname{Pr}\{N(t+\Delta t)=j \mid N(t)=$ the $m$ th case of state $i\}, j \in \Omega$

where, $m(I)=1,2, \ldots, M_{i}$ and:

$$
\sum_{m(i)=1}^{M_{i}} P_{i m(i)}(t)=1
$$

Based on these definition, we have:

$$
\begin{aligned}
& P_{i j}(t)=\operatorname{Pr}\{N(t+\Delta t)=j \mid N(t)=i\} \\
& P_{i j}(\Delta t)=\sum_{m(i)=1}^{M_{i}} P_{i m(i)}(\Delta t) P_{m(i) j}(\Delta t)
\end{aligned}
$$

$\left(\begin{array}{l}\mathrm{n} \\ \mathrm{k}\end{array}\right)$ :combinational formula $\mathrm{n} ! /[\mathrm{k} !(\mathrm{n}-\mathrm{k}) !]$

$\Delta=$ Transition rate matrix

$P_{j}(t)=\operatorname{Pr}\{N(t)=j\},, j \in \Omega$ the probability that the system in state $\mathrm{j}$

$P(t)=$ Matrix of state probabilities $P_{j}(t)$

$$
P_{j}(s)=\int_{0}^{\infty} e^{-s t} P_{j}(t) d t
$$

$\mathrm{A}(\mathrm{t}), \mathrm{R}(\mathrm{t})$ : [availablity, reliability] of the system:

$$
\text { MTTF }=\lim _{s \rightarrow 0} R^{*}(s)=\lim _{s \rightarrow 0} \int_{0}^{\infty} e^{-s t} R(t) d t
$$

\section{MATHEMATICAL DESCRIPTION}

For $\mathrm{j} \neq \mathrm{i}$, let:

$$
\mathrm{P}_{\mathrm{m}(\mathrm{i}) \mathrm{j}}(\Delta \mathrm{t})=\mathrm{q}_{\mathrm{m}(\mathrm{i}) \mathrm{j}} \Delta \mathrm{t}+\mathrm{o}(\Delta \mathrm{t})
$$

Then we have:

$$
\mathrm{P}_{\mathrm{ij}}(\Delta \mathrm{t})=\mathrm{q}_{\mathrm{ij}} \Delta \mathrm{t}+\circ(\Delta \mathrm{t})
$$

where:

$$
\mathrm{q}_{i j}=\sum_{m(i)=1}^{M_{i}} P_{i m(i)} q_{m(i) j}
$$

and:

$$
\mathrm{P}_{\mathrm{ii}}(\Delta \mathrm{t})=1-\sum_{\mathrm{j} \neq \mathrm{i}} \mathrm{P}_{\mathrm{ij}}(\Delta \mathrm{t})=1-\sum_{\mathrm{j} \neq \mathrm{i}} \mathrm{q}_{\mathrm{ij}} \Delta \mathrm{t}+\mathrm{o}(\Delta \mathrm{t})
$$

If every case of $N(t)=i$ occurs with an equal probability then we have:

$$
P_{i m(1)}=1 / M_{i}, P_{i j}(\Delta t)=\left(\sum_{m(i)=1}^{M_{i}} q_{m(i) j} \Delta t\right) / M_{i}+o(\Delta t), j \neq i
$$

and:

$$
\mathrm{p}_{\mathrm{ii}}(\Delta \mathrm{t})=1-\frac{1}{\mathrm{M}_{\mathrm{i}}}\left(\sum_{\mathrm{j} \neq \mathrm{i}} \sum_{\mathrm{m}(\mathrm{i})=1}^{\mathrm{M}_{\mathrm{i}}} \mathrm{q}_{\mathrm{m}(\mathrm{i}) \mathrm{j}}\right) \Delta \mathrm{t}+\circ(\Delta \mathrm{t})
$$

Since, all components are assumed to be i.i.d., every case of $\mathrm{N}(\mathrm{T})=\mathrm{i}$ will have the same probability of occurrence if $\mathrm{M}_{\mathrm{i}}=1, \mathrm{P}_{\mathrm{ij}}(\Delta \mathrm{t})$ becomes the ordinary transition probability from state $i$ at time $t$ to state $j$ at time $\mathrm{t}+\Delta \mathrm{t}$. Thus, the ordinary transition probability is a special case of the generalized transition probability defined above.

We need to fined a mechanism to evaluate $M_{i}$ for $I \in \Omega$. In fact we only need to fined the number of different 
cases that a circular $C(k, n: G)$ system is in state $-i$, $\mathrm{M}_{\mathrm{i}}$ for $1 \leq \mathrm{i} \leq(\mathrm{n}-\mathrm{k})$ can be calculated (Yueqin and Guan, 2005) as:

$$
\begin{aligned}
M_{-i} & =\left(\begin{array}{l}
n \\
i
\end{array}\right)-N(n-i, i+1 ; k-1)+ \\
& \sum_{\ell=k}^{\min (n-i, 2(k-1))}(2 k-1-\ell) N(n-i-\ell, i-1 ; k-1)
\end{aligned}
$$

Where for $\mathrm{b}<\mathrm{a}$, we have:

$$
\begin{gathered}
\sum_{i=a}^{b} f(i)=0 \\
N(m, h, k-1)=\sum_{j=0}^{m^{*}}(-1)^{j}\left(\begin{array}{c}
h \\
j
\end{array}\right)\left(\begin{array}{c}
m+h-k j-1 \\
m-k j
\end{array}\right)
\end{gathered}
$$

and $\mathrm{m}^{*}=\min (\mathrm{h},\lfloor\mathrm{m} / \mathrm{k}\rfloor)$ and $\lfloor\mathrm{x}\rfloor$ represents the largest integer less than or equal to value $\mathrm{x}$.

\section{STATE TRANSITION PROBABILITIES}

Using the model descriptions, we can obtain the following expirations of the state transition probabilities of the system:

$$
P_{0 j}(\Delta t)=\left\{\begin{array}{l}
n \lambda \Delta t+\circ(\Delta t), j=-1 \\
1-n \lambda \Delta t+\circ(\Delta t), j=0 \\
o(\Delta t), \text { for all other j values }
\end{array}\right.
$$

For $1 \leq \mathrm{i} \leq(\mathrm{n}-\mathrm{k})$, we have:

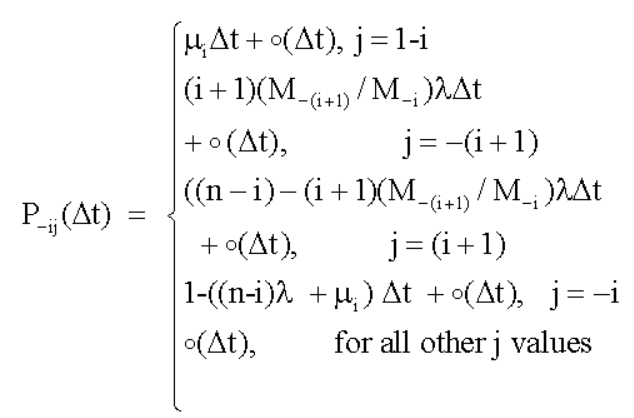

Where:

$$
\begin{aligned}
& \mu_{\mathrm{i}}=\mu \min (\mathrm{i}, \mathrm{r}) \\
& \mathrm{I}=1,2, \ldots \ldots,(\mathrm{n}-\mathrm{k})
\end{aligned}
$$

If the system in a failed state $i$, then among the $i$ failed components, the key components are under repair with priority by the repairman. Thus, we have:

$$
P_{i j}(\Delta t)=\left\{\begin{array}{l}
\eta_{i} \Delta t+o(\Delta t), j=1-i \\
1-\eta_{i} \Delta t+o(\Delta t), j=i \\
o(\Delta t), \text { for all other } j \text { values }
\end{array}\right.
$$

Where:

$$
\mathrm{M}_{\mathrm{i}}=\left(\begin{array}{l}
\mathrm{n} \\
\mathrm{i}
\end{array}\right)-\mathrm{M}_{-\mathrm{i}}
$$

and:

$$
\eta_{\mathrm{i}}=\sum_{\mathrm{k}=1}^{\mathrm{M}_{\mathrm{i}}} \mu \min \left(\mathrm{i}_{\mathrm{k}}, \mathrm{r}\right) / \mathrm{M}_{\mathrm{i}}
$$

$\mathrm{i}_{\mathrm{k}}$ is the number of key component in the kth case for the given state $i, i=1,2, \ldots,(n-k+1)$. Where Eq. 1 and 3 and most cases of Eq. 2 can be easily obtained based on the model descriptions and assumptions. Equation 2 when $\mathrm{j}=-(i+1)$ deserves some explanations. Because all components in the system are identical and the failure rate of each component is $\lambda$, every case of state $-i$ occurs with an equal probability i.e., $P_{\text {im(i) }}=1 / M_{i}$. By the model assumptions and the notation of the generalized transition probability, we have:

$$
\begin{aligned}
\mathrm{P}_{-\mathrm{i},-(\mathrm{i}+1)}(\Delta \mathrm{t})= & (\{\text { total number of ways totransit } \\
& \text { from state }-\mathrm{i} \text { to state }-(\mathrm{I}+1)\} \times \\
& \lambda \Delta \mathrm{t}) / \mathrm{M}_{-1}+\mathrm{o}(\Delta \mathrm{t})
\end{aligned}
$$

We know that each case of state $-(i+1)$ is the result of transition from state $-i$ and there are $i+1$ possible ways of transition from state $-i$ to state $-(i+1)$ while there are $M$. $(i+1)$ cases for the system to be in state $-(i+1)$. Thus, the total number of ways of transition from state $-i$ to state $-(i+1)$ is equal to $(i+1) M_{(i+1)}$. As a result, Eq. 2 when $\mathrm{j}=-(\mathrm{i}+1)$ is established. According to the expressions of the state transition probability for the system, we can find the transition rate matrix $\Lambda$ as follows:

$$
\begin{gathered}
\Delta=\left[\mathrm{q}_{\mathrm{ij}}\right], \mathrm{i}, \mathrm{j} \in \Omega \\
\mathrm{q}_{\mathrm{ij}}=\lim _{\Delta t \rightarrow 0} \frac{\mathrm{p}_{\mathrm{ij}}(\Delta \mathrm{t})}{\Delta \mathrm{t}}, \mathrm{i}, \mathrm{j} \in \Omega \text { and } \mathrm{i} \neq \mathrm{j} \\
\mathrm{q}_{\mathrm{jj}}=\lim _{\Delta t \rightarrow 0} \frac{1-\mathrm{p}_{\mathrm{j} j}(\Delta \mathrm{t})}{\Delta \mathrm{t}}, \mathrm{j} \in \Omega
\end{gathered}
$$

The transition probability $P_{j}(t), j \in \Omega$ is defined as the probability for the system to being in state $\mathrm{j}$ at time $\mathrm{t}$. This probability can be viewed according to KolmogorovFeller forward equation, we have:

$$
\left\{\begin{array}{l}
\mathrm{dP}(\mathrm{t}) / \mathrm{dt}=\mathrm{P}(\mathrm{t}) \times \Lambda \\
\mathrm{P}(0)=(1,0,0, \ldots, 0)
\end{array}\right.
$$

By introducing the Laplace transform of the state Eq. 4 with constant failure and repair rates we obtain the algebraic system has the form: 


$$
\begin{aligned}
& {\left[\mathrm{sP}_{0}(\mathrm{~s})-1 \mathrm{sP}_{-1}(\mathrm{~s}) \ldots \mathrm{sP} \mathrm{P}_{-(\mathrm{n}-\mathrm{k})}(\mathrm{s}) \mathrm{sP}_{2}(\mathrm{~s}) \ldots . \mathrm{s} \mathrm{P}_{(\mathrm{n}-\mathrm{k}+1)}(\mathrm{s})\right]=} \\
& {\left[\mathrm{P}_{0}(\mathrm{~s}) \mathrm{P}_{-1}(\mathrm{~s}) \ldots \mathrm{P}_{-(\mathrm{n}-\mathrm{k})}(\mathrm{s}) \mathrm{P}_{2}(\mathrm{~s}) \ldots . \mathrm{P}_{(\mathrm{n}-\mathrm{k}+1)}(\mathrm{s})\right] \Lambda}
\end{aligned}
$$

From Eq. 5 and taking inverse Laplace, we get the conventional availability function of the system:

$$
A_{c}(t)=P_{0}(t)+\sum_{j=1}^{n-k} P_{-j}(t)
$$

To obtain the reliability of the system, we consider a continuous time homogeneous Markov process $\{\tilde{\mathrm{N}}(\mathrm{t}), \mathrm{t} \geq 0\}$ with $\mathrm{n}-\mathrm{k}$ absorbing states. Obviously, the difference between the Markov $\{\mathrm{N}(\mathrm{t}), \mathrm{t} \geq 0\}$ and is that $\{\tilde{\mathrm{N}}(\mathrm{t}), \mathrm{t} \geq 0\}$ the set of failed states in $\{\mathrm{N}(\mathrm{t}), \mathrm{t} \geq 0\}$ becomes the set of absoring states in $\{\tilde{\mathrm{N}}(\mathrm{t}), \mathrm{t} \geq 0\}$. Now, let:

$$
\tilde{P}_{j}(t)=\operatorname{Pr}[\tilde{N}(t)=j], j \in \Omega
$$

From Eq. 5 and taking inverse Laplace, we get the conventional reliability function of the system:

$$
R_{c}(t)=\tilde{P}_{0}(t)+\sum_{j=1}^{n-k} \tilde{P}_{-j}(t)
$$

The MTTF of the system is given by:

$$
\mathrm{MTTF}_{\mathrm{S}}=\int_{0}^{\infty} \mathrm{R}(\mathrm{t}) \mathrm{dt}=\lim _{\mathrm{s} \rightarrow 0} \int_{0}^{\infty} \mathrm{e}^{-\mathrm{st}} \mathrm{R}(\mathrm{t}) \mathrm{dt}
$$

The membership function of the fuzzy success state of the consecutive-k-out-of-n:G system: In the circular consecutive-k-out-of-n: $G$ system, let the universe of discourse be $\Omega=\{0,-1,-2, \ldots,-(n-k), 2,3, \ldots,(n-k+1)\})\}$, the set of working states is $\mathrm{W}=\{0,-1,-2, \ldots,-(\mathrm{n}-\mathrm{k})\}$ and the set of failed states is $\mathrm{F}=\{2,3, \ldots,(\mathrm{n}-\mathrm{k}+1)\}$. On this universe, we can find the system fuzzy success state $\mathrm{W}$ with the membership function: $K_{j}(W)$ for $j=1,2, \ldots,(n-k)$ (Jiancheng and $\mathrm{Wu}, 2006$ ):

$$
\begin{aligned}
& \mathrm{K}_{\mathrm{j}}(\mathrm{W})=\frac{(\mathrm{n}-\mathrm{k}+1)-\mathrm{j}}{\mathrm{n}-\mathrm{k}+1}=1-\frac{\mathrm{j}}{\mathrm{n}-\mathrm{k}+1} \\
& \mathrm{j}=1,2, \ldots,(\mathrm{n}-\mathrm{k})
\end{aligned}
$$

In this case, the system profust availability function is defined as:

$$
A_{p}(t)=P_{0}(t)+\sum_{j=1}^{n-k} K_{j}(W) P_{-j}(t)
$$

and the system profust reliability function is defined as:

$$
R_{p}(t)=\tilde{P}_{0}(t)+\sum_{j=1}^{n-k} K_{j}(W) \tilde{P}_{-j}(t)
$$

\section{CIRCULAR C (7, 10:G) REPAIRABLE SYSTEM WITH $r=3$}

The working time and the repair time of each component are both exponentially distributed: For a closed recurring water supply system in a thermoelectric plant, there are ten pumps and 3 repairman.

The system works if and only if at least 7 consecutive water pumps in the system are working. According to study, the state space $\Omega=\{0,-1,-2,-3,2,3,4\}$, the set of working state $W=\{0,-1,-2,-3\}$ and the set of failed state $F=\{2,3,4\}$ of the system. By using the expressions of the state transition probability of we can calculate the $\Delta$ transition rate matrix :

$\Lambda=\left[\begin{array}{ccccccc}0 & -1 & -2 & -3 & 2 & 3 & 4 \\ -10 \lambda & 10 \lambda & 0 & 0 & 0 & 0 & 0 \\ \mu & -\mathrm{d}_{1} & 4 \lambda & 0 & 5 \lambda & 0 & 0 \\ 0 & 2 \mu & -\mathrm{d}_{2} & 6 \lambda & 0 & 2 \lambda & 0 \\ 0 & 0 & 3 \mu & -\mathrm{d}_{3} & 0 & 0 & 7 \lambda \\ 0 & \frac{6 \mu}{5} & 0 & 0 & \frac{-6 \mu}{5} & 0 & 0 \\ 0 & 0 & \frac{116 \mu}{110} & 0 & 0 & \frac{116 \lambda}{110} & 0 \\ 0 & 0 & 0 & 0 & 0 & 0 & 0\end{array}\right]$

Where $\left.\mathrm{d}_{\ell}=[910-\ell) \lambda+\ell \mu\right]$ for $\ell=1,2,3$

From Eq. 5, 6 and 12, we have:

$$
\begin{gathered}
(\mathrm{s}+10 \lambda) \mathrm{P}_{0}(\mathrm{~s})-\mu \mathrm{P}_{-1}(\mathrm{~S})=1 \\
-10 \lambda \mathrm{P}_{0}(\mathrm{~s})+\left[\left(\mathrm{s}+\mathrm{d}_{1}\right)-6 \lambda \mu /(\mathrm{s}+6 \mu / 5)\right] \\
\mathrm{P}_{-1}(\mathrm{~s})-2 \mu \mathrm{P}_{-2}(\mathrm{~s})=0 \\
-4 \lambda \mathrm{P}_{-1}(\mathrm{~s})+\left[\left(\mathrm{s}+\mathrm{d}_{2}\right)-116 \lambda \mu / 55(\mathrm{~s}+116 \mu / 110)\right] \times \\
\mathrm{P}_{-2}(\mathrm{~s})-3 \mu \mathrm{P}_{-3}(\mathrm{~s})=0 \\
-6 \lambda \mathrm{P}_{-2}(\mathrm{~s})+\left(\mathrm{s}+\mathrm{d}_{3}\right) \mathrm{P}_{-3}(\mathrm{~s})=0
\end{gathered}
$$

By taking inverse Laplace, we get the conventional availability is: 


$$
\left.\mathrm{A}_{\mathrm{c}}(\mathrm{t})=\mathrm{P}_{0}(\mathrm{t})+\sum_{\mathrm{j}=1}^{3} \mathrm{P}_{\mathrm{j}}(\mathrm{t}) \quad(\mathrm{MTTF})_{\mathrm{c}}=\lim _{\mathrm{s} \rightarrow 0} \mathrm{R}_{\mathrm{c}}{ }^{*}(\mathrm{~s})=\lim _{\mathrm{s} \rightarrow 0}\left(\tilde{\mathrm{P}}_{0}(\mathrm{~s})\right)+\sum_{\mathrm{j}=1}^{3} \tilde{\mathrm{P}}_{\mathrm{j}}(\mathrm{s})\right)=0.7393
$$

By taking inverse Laplace, we get the profust availability is:

$$
A_{p}(t)=P_{0}(t)+\sum_{j=1}^{3}\left(1-\frac{j}{4}\right) P_{-j}(t)
$$

Now for $\lambda=0.5$ and $\mu=1.5$, we can use the previous equation to study the effect of increasing time on $\mathrm{A}(\mathrm{t})$. As shown in Fig. 1. From Eq. 5, 7 and 12, we have:

$$
\left\{\begin{array}{l}
(\mathrm{s}+10 \lambda) \tilde{\mathrm{p}}_{0}(\mathrm{~s})-\mu \tilde{\mathrm{P}}_{-1}(\mathrm{~s})=1 \\
-10 \lambda \tilde{\mathrm{P}}_{0}(\mathrm{~s})+\left(\mathrm{s}+\mathrm{d}_{1}\right) \tilde{\mathrm{P}}_{-1}(\mathrm{~s})-2 \mu \tilde{\mathrm{P}}_{-2}(\mathrm{~s})=0 \\
-4 \lambda \tilde{\mathrm{P}}_{-1}(\mathrm{~s})+\left(\mathrm{s}+\mathrm{d}_{2}\right) \tilde{\mathrm{P}}_{-2}(\mathrm{~s})-3 \mu \tilde{\mathrm{P}}_{-3}(\mathrm{~s})=0 \\
-6 \lambda \tilde{\mathrm{P}}_{-2}(\mathrm{~s})+\left(\mathrm{s}+\mathrm{d}_{3}\right) \tilde{\mathrm{P}}_{-3}(\mathrm{~s})=0
\end{array}\right.
$$

By taking inverse Laplace, we get the conventional reliability is:

$$
R_{c}(t)=\tilde{P}_{0}(t)+\sum_{j=1}^{3} \tilde{P}_{j}(t)
$$

By taking inverse Laplace, we get the profust reliability is:

$$
R_{p}(t)=\tilde{P}_{0}(t)+\sum_{j=1}^{3}\left(1-\frac{j}{4}\right) \tilde{P}_{-j}(t)
$$

Now for $\lambda=0.5$ and $\mu=1.5$, we can use the previous equation to study the effect of increasing time on $\mathrm{R}(\mathrm{t})$ as shown in Fig. 2. The MTTF of the system when $\lambda=0.5$ and $\mu=1.5$ is given by:

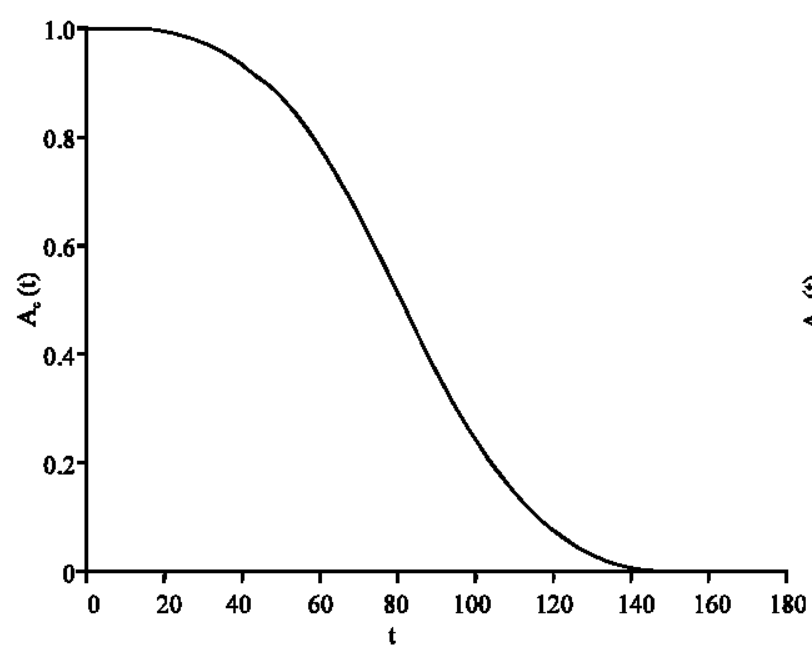

Fig. 3: The plots of the availability $A_{c}(t)$ and $A_{p}(t)$ with $\lambda(t)$ and $\mu(t)$ against time $t$
Where:

$\left.(\mathrm{MTTF})_{\mathrm{p}}=\lim _{\mathrm{s} \rightarrow 0} \mathrm{R}_{\mathrm{p}}{ }^{*}(\mathrm{~s})=\lim _{\mathrm{s} \rightarrow 0}\left(\tilde{\mathrm{P}}_{0}(\mathrm{~s})\right)+\sum_{\mathrm{j}=1}^{3}\left(1-\frac{\mathrm{j}}{4}\right) \tilde{\mathrm{P}}_{\mathrm{j}}(\mathrm{s})\right)=0.5778$

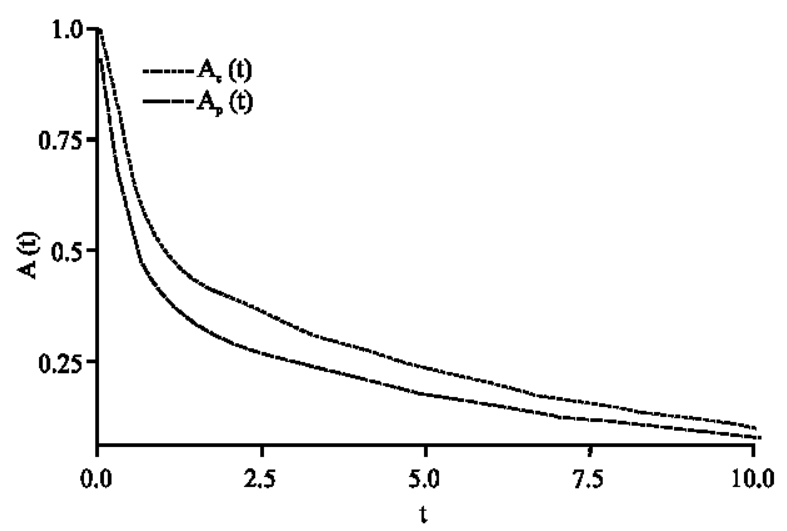

Fig. 1: The plots of the availability against time $t$

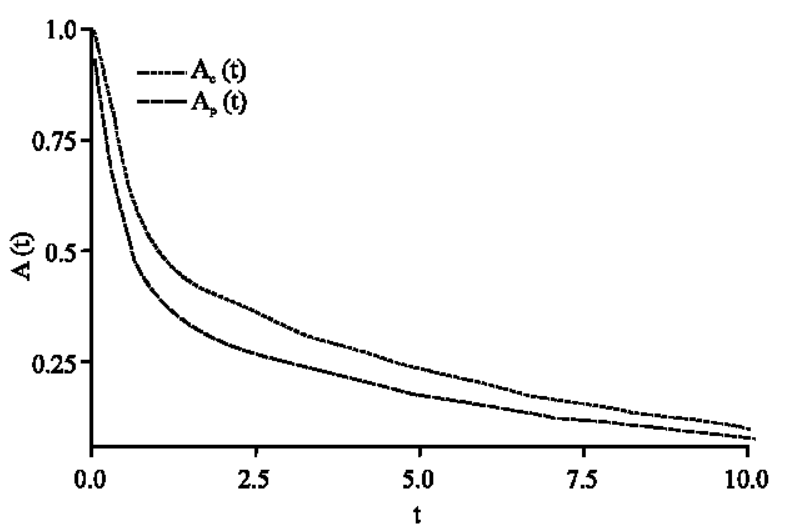

Fig. 2: The plots of the availability against time

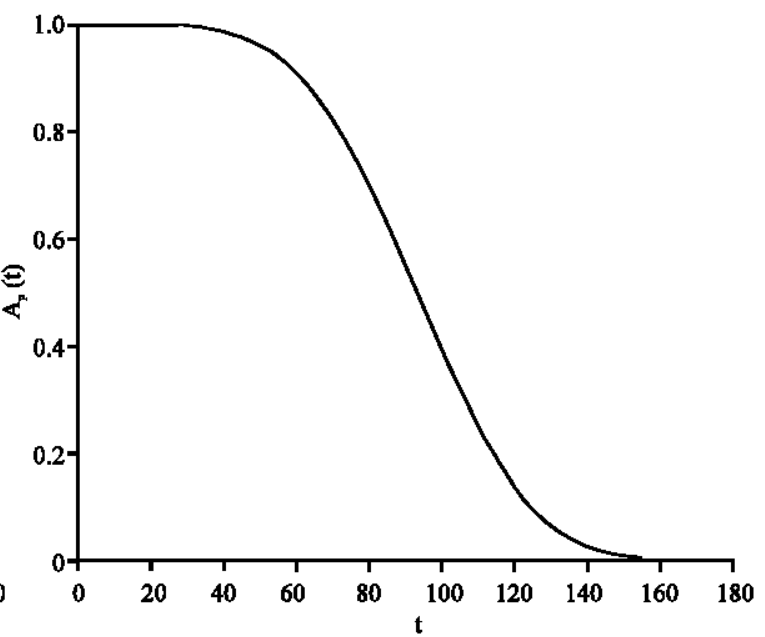



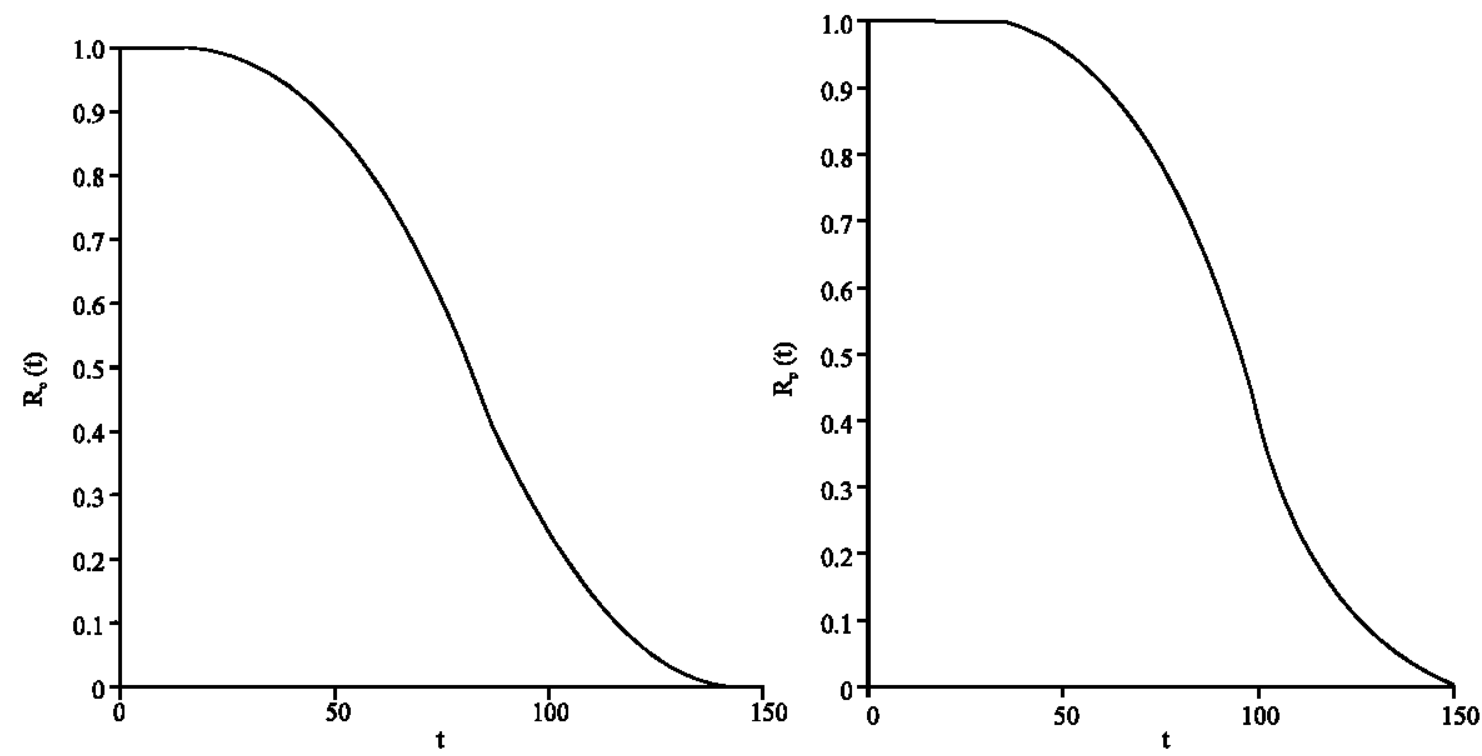

Fig. 4: The plots of the availability $\mathrm{R}_{c}(\mathrm{t})$ and $\mathrm{R}_{\mathrm{p}}(\mathrm{t})$ with $\lambda(\mathrm{t})$ and $\mu(\mathrm{t})$ against time $\mathrm{t}$

The working time and the repair time of each component are both Weibull distributed: As a particular case, let us assume that the working time and the repair time of each component are both Weibull distributed. We can then write:

$$
\lambda=\lambda(\mathrm{t})=\frac{2.933}{(138.07)^{2.933}} \mathrm{t}^{1.933}
$$

and:

$$
\mu=\mu(t)=\frac{1.79}{(111.66)^{1.79}} t^{0.79}
$$

By setting $\lambda=\lambda(\mathrm{t})$ and $\mu=\mu(\mathrm{t})$ in Eq. 12. the system conventional availability and profust availability against time $\mathrm{t}$ are shown in Fig. 3 with numerical solutions based on Runge-Kutta method. Also, under the assumption that the working time and the repair time of each component are both Weibull distributed, the system conventional reliability and profust reliability against time $t$ are shown in Fig. 4 with numerical solutions based on Runge-Kutta method.

\section{REFERENCES}

Chang, J.C., L.R. Cui and F.K. Hwang, 2000. Reliabilities of Consecutive-K Systems. 1st Edn., Kluwer Academic, Boston, London, ISBN: 0792366611.

Cheng, K. and Y.L. Zhang, 2001. Analysis for a consecutive-k-out-of-n: $F$ repairable system with priority in repair. Int. Syst. Sci., 32: 591-598.

Gera, A.E., 2000. A consecutive-k-out-of-n: G system with dependent elements-a matrix formulation and solution. Reliab. Eng. Syst. Safety, 68: 61-67.
Hwang, F.K., L.R. Cui, J.C. Chang and W.D. Lin, 2000. Comments, on reliability and component importance of a consecutive-k-out-of-n system, by Zuo. Microelectronic Reliab., 40: 1061-1063.

Jiancheng, G. and Y. Wu, 2006. Repairable consecutive- kout-of-n: F system with fuzzy states. Fuzzy Sets Syst., 157: $121-142$.

Kuo, W. and M.J. Zuo, 2003. Optimal Reliability Modeling: Principles and Applications. John Wiley and Sons, Inc., New Jersy, pp: 544.

Kuo, W., W. Zhang and M. Zuo, 1990. A consecutive-kout-of-n: $\mathrm{G}$ system: The mirror image of $\mathrm{A}$ consecutive-k-out-of-n: F system. IEEE Trans. Reliab., 39: 244-253.

Rade, L., 1994. A consecutive-k-out-of-n reliability system in random environment. Microelectronic Reliab., 34: 1311-1319.

Yam, R.C.M., M.J. Zuo and Y.L. Zhang, 2003. A method for evaluation of reliability indices for repairable circular consecutive-k-out-of-n: F systems. Reliab. Eng. Syst. Safety, 79: 1-9.

Yueqin, W. and J. Guan, 2005. Repairable consecutive-kout-of-n: G systems with $\mathrm{r}$ repairmen. IEEE Trans. Reliab., 54: 328-337.

Zhang, Y.L. and H.N. Lin, 2000. Linear consecutive-2-outof-n:F repairable system with markov dependence and priority in repair. Acta Automatica Sinica, 26: 317-323.

Zhang, Y.L. and Y. Lam, 1998. Reliability of consecutive-kout-of-n: G repairable system. Int. J. Syst. Sci., 29: 1375-1379.

Zhang, Y.L., M.J. Zuo and R.C.M. Yam, 2000. Reliability analysis for a circular consecutive-2-out- of-n: F repairable system with priority in repair. Reliab. Eng. Syst. Safety, 68: 113-120. 